\title{
Flipped Classroom Approach in Rigid Body Dynamics: A Case Study of Five-Semester Observation
}

\author{
https://doi.org/10.3991/ijep.v11i1.15005 \\ Mohd Hasnun Arif Hassan ${ }^{(凶)}$, Nur Aqilah Othman \\ Universiti Malaysia Pahang, Pekan, Malaysia \\ mhasnun@ump.edu.my
}

\begin{abstract}
The flipped classroom is an alternative approach to the conventional lecture by introducing collaborative tasks in the class to promote active learning. The theoretical lecture was delivered to the students through videos, which they watch at home before the class. The implementation of this method at the undergraduate level especially in engineering courses was reported to be lacking. This study presents a five-semester observation in the Rigid Body Dynamics course, during which the first two semesters were conducted using the conventional approach, and the following three semesters were flipped. Three indicators were measured to evaluate the effectiveness of the method: the percentage of failures, the number of student enrolments, and the lecturer evaluation score. There is strong evidence showing that flipped classroom has increased the student's performance. Also, it was found that the students prefer this method compared to the conventional approach. This study demonstrates that the flipped classroom approach can be implemented in engineering courses with a good chance of success.
\end{abstract}

Keywords-Flipped classroom, video lecture, rigid body dynamics, engineering

\section{$1 \quad$ Introduction}

The term 'flipped classroom' was coined in 2011 where studies have shown that students were having difficulties in their undergraduate studies due to the passive role they play in the class [1]. The word 'flipped' indicates that the approach is the opposite of the conventional method, that is the theoretical lecture is learned at home through videos [2], and collaborative tasks are given to the students in the class [3].

The flipped classroom approach has been implemented in schools [4]. This approach has been reported by many in English language courses [5], [6] and mathematics [7], [8]. However, its implementation at the undergraduate level especially in engineering courses is scarce [9], [10]. This paper presents an observation of the implementation of the flipped classroom approach in the Rigid Body Dynamics course, a fundamental course taken by most of the Mechanical Engineering students in their first year.

This course covers rigid body kinematics and kinetics of two-dimensional (2D) planar motions. At the end of the course, the students should be able to analyze the 
position, velocity, and acceleration of a 2D planar mechanism. Further, by applying either the principle of force-acceleration, impulse-momentum, or work-energy, the students should be able to solve kinetics problems of 2D planar motion. This course also requires the students to design a $2 \mathrm{D}$ planar mechanism that performs a specific function. It carries three credits and consists of five course outcomes, which are mainly derived from the contents of the course.

The objective of this paper is to evaluate the effectiveness of the flipped classroom approach in the Rigid Body Dynamics course at Universiti Malaysia Pahang. The results are presented based on the analyses conducted from several indicators recorded within five semesters of five different cohorts of students.

\section{Method}

This study presents an observation of a five-semester lecture of the Rigid Body Dynamics course delivered to five different cohorts. Within these five semesters, the first two semesters were conducted using the conventional approach, that is by delivering the theoretical lecture in the class, as well as some tutorial sessions. Another three subsequent semesters were conducted using the flipped classroom approach.

\subsection{Flipped classroom}

In the flipped classroom approach, the theoretical lecture was given through online videos posted on YouTube. There are altogether 11 videos that cover four chapters of Rigid Body Dynamics. The students were asked to watch the video before the face-toface classes. This course consists of four hours of face-to-face every week, which is divided into two 2-hour sessions. These videos were shared with the students one-byone before the tutorial session. Besides, a YouTube playlist comprises of all 11 videos was given to the students.

\subsection{Evaluation indicators}

As mentioned earlier, within these five semesters, two different approaches were implemented in delivering the content, that is the conventional method and the flipped classroom method. The effectiveness of the flipped classroom approach in this course was evaluated using three indicators: The percentage of failed students in a cohort, the number of students enrolled in the class, and the lecturer evaluation score.

The number of failed students in each cohort is the first indicator used to evaluate the effectiveness of the approach. Rigid Body Dynamics is known as one of the 'killer' courses among Mechanical Engineering students. The number of failures is often high. Thus, the number of failed students before and after the implementation of the flipped classroom is thought of as one of the good indicators.

Universiti Malaysia Pahang utilizes an open registration system, whereby the students register for their classes instead of following a structured curriculum. For courses with the high number of student enrolment, the classes are split into several sections of 
60 students. The students register in the section on a first-come-first-serve basis, in which they choose their preferred time slot and lecturer. The preference of students towards a particular lecturer and class might indicate the effectiveness of the lecture approach by the particular lecturer. Hence, this is also used as an indicator for evaluation.

Further, every semester the students are required to evaluate the performance of the lecturer twice, once in the middle of the semester, and before sitting for the final examination. Failing to evaluate the performance of the lecturer will result in the students being barred from sitting for the final examination. The evaluation is performed online by answering several questions in the form of a Likert scale. Besides, the students are encouraged to write their opinions on the teaching approach. The score of this evaluation is used as another indicator to measure the effectiveness of the approach.

\section{$3 \quad$ Results and Discussions}

This observation was conducted from Semester 2 Session 2016/2017 until Semester 2 Session 2018/2019. The first two semesters (Semester 2 2016/2017 and Semester 1 $2017 / 2018$ ) were conducted using the conventional lecture method. The following three semesters (Semester 2 2017/2018, Semester 1 2018/2019, and Semester 2 2018/2019) were conducted using the flipped classroom approach as described in the previous section.

\subsection{Number of failed students}

The first indicator to be observed is the number of failed students in this course. Figure 1 shows the percentage of failed students in each semester. The percentage was used instead of the number of students since percentage represents a more accurate representation of the data, since the number of students in the class varies from one semester to another as a result of the open registration approach mentioned earlier. The first two semesters indicated by blue-colored bars represent the percentage of students who failed during which the conventional lecture method was used. The following three semesters showed by the magenta-colored bars depict the percentage of failed students during which the flipped classroom approach has been implemented.

It is evident from Figure 1 that a significant drop in the number of failed students was observed when the flipped classroom approach was implemented. The number of failed students was very high (more than half) in the first semester. A dropped was seen in the second observed semester, however, this is attributed to the small number of students registered in this particular semester. In Semester 2 2017/2018, a significant drop was observed, whereby the percentage of failed students plummeted to only $7.41 \%$. Another drop was seen in the subsequent semester whereby a mere $3.13 \%$ of students failed the course. This percentage maintains at around $5 \%$ in the following semester. By looking at Figure 1, we are certain that the flipped classroom approach has improved the knowledge delivery in Rigid Body Dynamics that is portrayed by the minimal percentage of failed students in every cohort. 


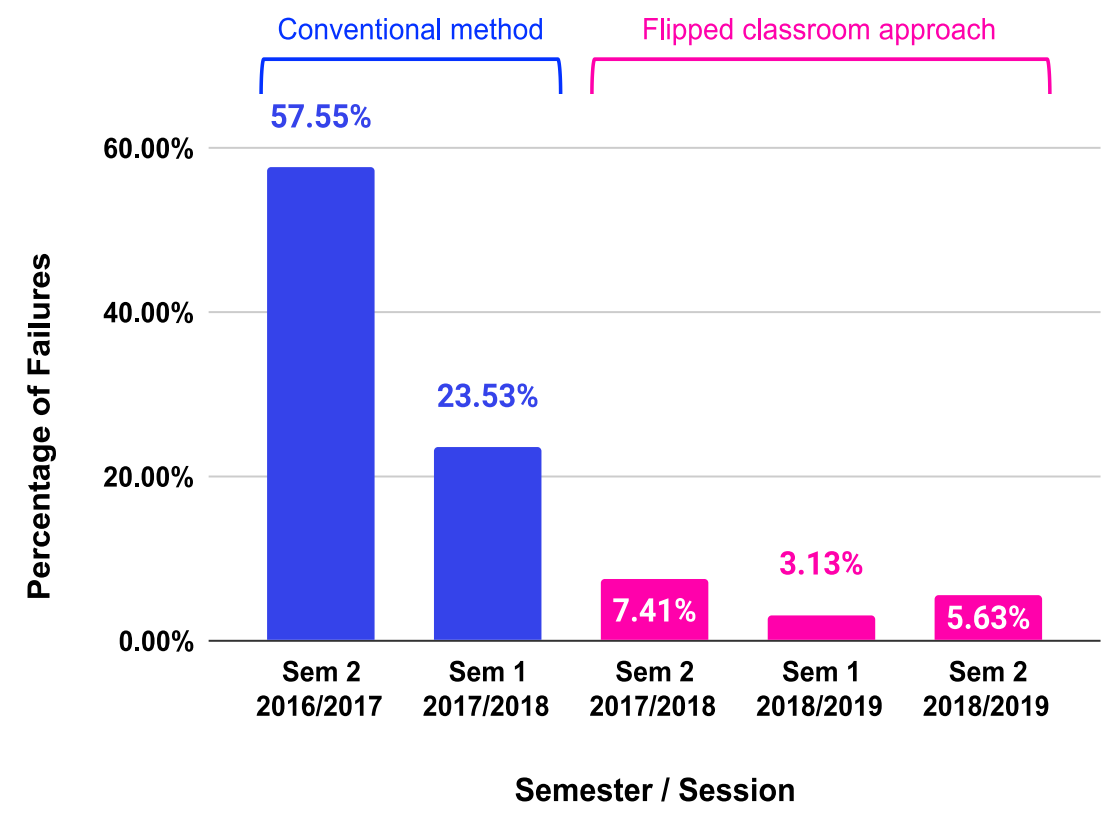

Fig. 1. The percentage of students failed in the course

\subsection{Number of students' enrolment}

Another indicator of a successful and effective class/lecture is the number of students enrolled in the section (class) of a particular lecturer. The number of enrolments was taken as one of the indicators of the effectiveness of the flipped classroom approach. It is hypothesized that if the students like the approach, it will be reflected in the number of enrolments in a particular section (class). Figure 2 shows the number of enrolments in the section (class) taught by the first author observed during these five semesters.

There were 52 students enrolled in the first semester of the observation. As mentioned previously, there were $57.55 \%$ failures in this cohort. Thus, the number of enrolments dropped significantly (67\% drop in enrolment) in the following semester. We speculated that the students were avoiding the class of the first author due to the high number of failures in the previous semester. In the subsequent semester (Semester 2 2017/2018), in which the flipped classroom approach was first introduced (orange-colored bars), the number of enrolments increased slightly, although this was not due to the introduction of the new approach since it was never mentioned to the students before the semester begin that the flipped classroom method will be implemented. 


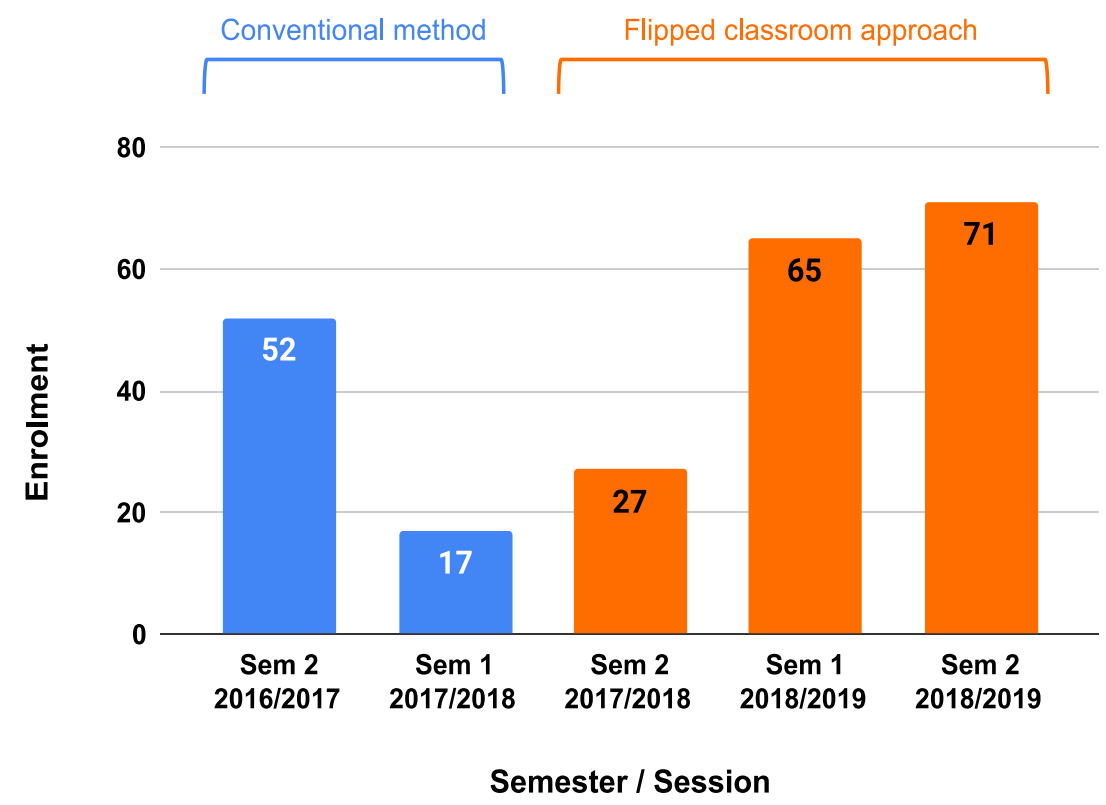

Fig. 2. Enrolment in the class of the first author each semester

However, it is very interesting to see that in the second semester of the flipped classroom implementation, the number of enrolments increased dramatically ( $141 \%$ increase was seen). Although there was no hard evidence showing that this increase was due to the flipped classroom approach, we saw a steady increase in the following semester, with 71 students enrolled in the class. On another note, when comparing to another section (class), the number of students enrolled in Semester 1 2018/2019 in Section 2 was only 23 students compared to 65 students enrolled in Section 1 (the class taught by the first author). We take this as a good sign of acceptance or preference of the flipped classroom approach over the conventional lecture method among engineering students in Universiti Malaysia Pahang.

\subsection{Lecturer's evaluation score}

The third indicator that we use to evaluate the effectiveness of the flipped classroom approach is how the lecturer (in this case the first author of this paper) was rated by the students before and after the implementation of the flipped classroom method. We hypothesized that if there was no significant change in the score, it means that the newly implemented approach does not affect student acceptance. However, if there is a noticeable increase in the score after the implementation of the flipped classroom approach, this might indicate that the method is preferred by the students, thereby increasing their eagerness to learn. Figure 3 shows the lecturer evaluation score of the first author as rated by five different cohorts of students. 


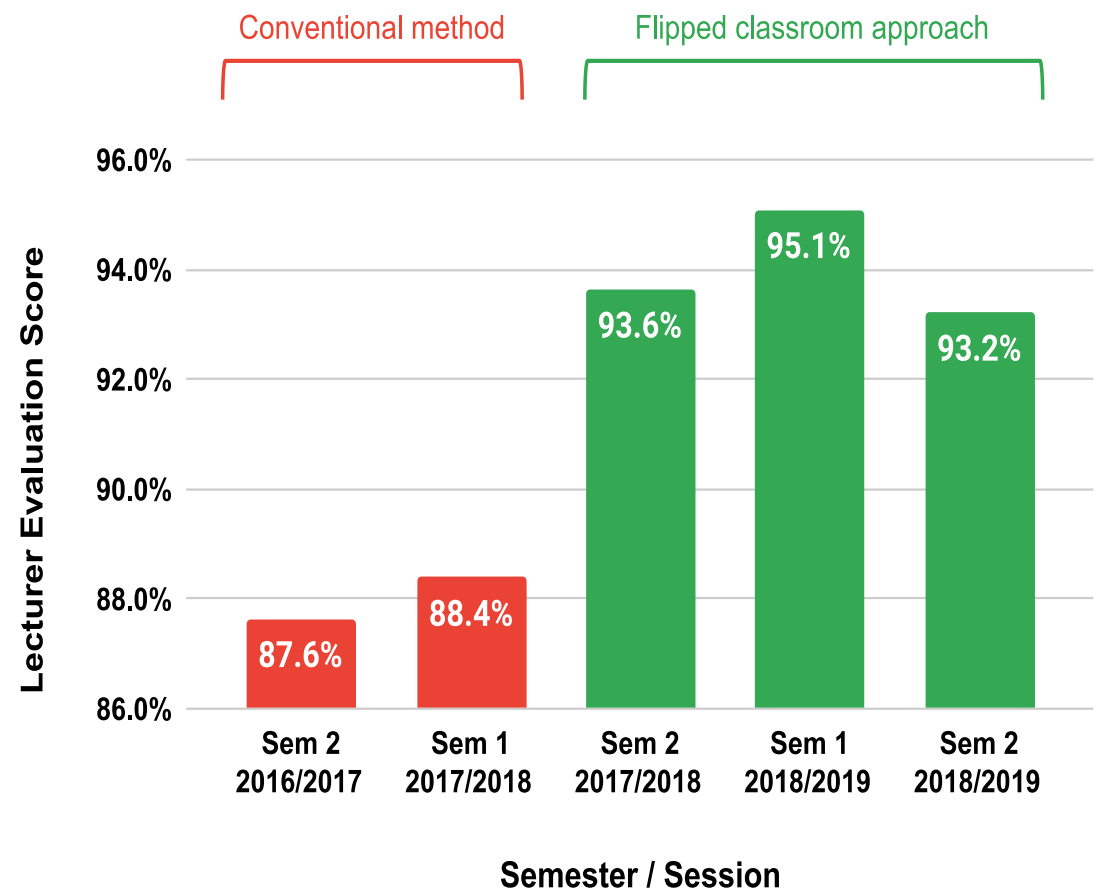

Fig. 3. Lecturer evaluation score of every observed semester as rated by the students

It is evident that in the first two observed semesters (red-colored bars), in which the conventional lecture method was used, the lecturer was rated $88 \%$ on average. Nevertheless, once the flipped classroom approach was implemented in the third observed semester onwards, a notable rise in the score was seen. In the third observed semester (Semester 2 2017/2018), the first author was rated 93.6\%, and the rating increased in the following semester to $95.1 \%$. In the last observed semester (Semester 2 2018/2019), although there was a slight decrease in the score, the score remained above $90 \%$, which indicates an excellent rating by the students.

In addition to the rating, some of the students also provided their comments on the way the lecture was conducted. Table 1 shows some selected comments by the students on how they appreciate the use of the flipped classroom approach in this course. The question asked in the survey was "What Did You Especially Like About the Lecturers Teaching Techniques?".

The comments shown in Table 1 further corroborate our observation that the implementation of the flipped classroom approach in Rigid Body Dynamics was preferred and accepted by the students. The students seem to prefer this approach as compared to the conventional lecture, which agrees with previously publish study on a similar course [11]. 
Table 1. Some selected comments by the students on the flipped classroom approach.

\begin{tabular}{|l|}
\hline \multicolumn{1}{|c|}{ What Did You Especially Like About the Lecturers Teaching Techniques? } \\
\hline $\begin{array}{l}\text { He is one of the best lecturers. He gave very good exercises and explained them in detail. Video lectures } \\
\text { explain the theory very well. }\end{array}$ \\
\hline The effort which he puts into making the videos for students. Detailed step-by-step guidance in tutorials. \\
\hline $\begin{array}{l}\text { He provided the notes and videos to the students before class. Always give more explanation in the class. } \\
\text { The lecturer explained the subject well. The video makes me understand more. }\end{array}$ \\
\hline I love how he taught me and the rest using video and face-to-face. \\
\hline Very creative and put a lot of effort in teaching the students. \\
\hline $\begin{array}{l}\text { He has a very unique way of teaching the students. He will always upload the study materials beforehand. } \\
\text { When we face any problem, he will patiently teach us the easiest way to solve the question. }\end{array}$ \\
\hline
\end{tabular}

\section{Conclusion}

This paper presents a five semesters observation, in which two initial semesters were conducted using conventional lectures, and the following three semesters were delivered through the flipped classroom approach. Three indicators were used to evaluate the effectiveness of the approach, that is using the percentage of failed students, the number of enrolments in the class, and the lecturer evaluation score given by the enrolled students. It is apparent from the findings that the use of the flipped classroom approach in the Rigid Body Dynamics course has improved the students' understanding and performance. This is indicated by the low percentage of failures when the approach was implemented. Further, it was found that the flipped classroom approach was preferred by the students based on the number of enrolments in the class, as well as the lecturer evaluation score rated by the students. The findings of this paper demonstrate that the flipped classroom approach in Rigid Body Dynamics is successful not only in terms of improving the performance of the students, but also increasing their learning dedication. The on-demand delivery of theoretical lecture through videos provide the students with more flexibility, whereby they choose their preferred time to learn the theory and if necessary, they can repeat the lecture to improve their understanding of the content.

\section{$5 \quad$ References}

[1] T. M. Andrews, M. J. Leonard, C. A. Colgrove, and S. T. Kalinowski, "Active learning not associated with student learning in a random sample of college biology courses," CBE Life Sci. Educ., 2011. https://doi.org/10.1187/cbe.11-07-0061

[2] C. Nwosisi, "Extended Study of the Flipped Instruction and Its Usefulness," Int. J. Online Biomed. Eng., vol. 15, no. 03, pp. 62-69, 2019. https://doi.org/10.3991/ijoe.v15i03.9841

[3] L. Abeysekera and P. Dawson, "Motivation and cognitive load in the flipped classroom: definition, rationale and a call for research," High. Educ. Res. Dev., 2015.

[4] S. A. Elian and D. A. Hamaidi, "The effect of using flipped classroom strategy on the academic achievement of fourth grade students in Jordan,” Int. J. Emerg. Technol. Learn., 2018. https://doi.org/10.3991/ijet.v13i02.7816 
[5] B. Santikarn and S. Wichadee, "Flipping the classroom for English language learners: A study of learning performance and perceptions,” Int. J. Emerg. Technol. Learn., 2018. https://doi.org/10.3991/ijet.v13i09.7792

[6] M. Y. Abdullah, S. Hussin, and K. Ismail, "Implementation of flipped class-room model and its effectiveness on English speaking performance,” Int. J. Emerg. Technol. Learn., 2019. https://doi.org/10.3991/ijet.v14i09.10348

[7] I. Braun, S. Ritter, and M. Vasko, "Inverted Classroom by Topic - A Study in Mathematics for Electrical Engineering Students,” Int. J. Eng. Pedagog., 2014. https://doi.org/10.3991/ ijep.v4i3.3299

[8] K. Umam, T. Nusantara, I. N. Parta, E. Hidayanto, and H. Mulyono, "An application of flipped classroom in mathematics teacher education programme," Int. J. Interact. Mob. Technol., 2019. https://doi.org/10.3991/ijim.v13i03.10207

[9] B. Kerr, "The flipped classroom in engineering education: A survey of the research," in Proceedings of 2015 International Conference on Interactive Collaborative Learning, ICL 2015, 2015. https://doi.org/10.1109/icl.2015.7318133

[10] J. Kanelopoulos, K. A. Papanikolaou, and P. Zalimidis, "Flipping the Class-room to Increase Students' Engagement and Interaction in a Mechanical Engineering Course on Machine Design,” Int. J. Eng. Pedagog., 2017. https://doi.org/10.3991/ijep.v7i4.7427

[11] R. Kandakatla, E. J. Berger, J. F. Rhoads, and J. DeBoer, "Student Perspectives on the Learning Resources in an Active, Blended, and Collaborative (ABC) Pedagogical Environment," Int. J. Eng. Pedagog., 2020. https://doi.org/10.3991/ijep.v10i2.11606

\section{Authors}

Dr. Mohd Hasnun Arif Hassan is a senior lecturer at the Faculty of Mechanical and Automotive Engineering Technology, Universiti Malaysia Pahang. He has been teaching Rigid Body Dynamics since 2016 and has been implementing the use of technology in the teaching. He considers himself a computer geek who likes to explore technology in his work especially in teaching.

Dr. Nur Aqilah Othman is a senior lecturer at the Faculty of Electrical and Electronics Engineering Technology. She has a passion for teaching and loves the idea of implementing technology in teaching. She has contributed to the data collection and the analysis of this paper.

Article submitted 2020-04-19. Resubmitted 2020-04-29. Final acceptance 2020-05-05. Final version published as submitted by the authors. 